\title{
KINERJA SUPPLY CHAIN MANAGEMENT GLASS EEL (BENIH SIDAT) UNTUK MENUNJANG INDUSTRI PEMBESARAN SIDAT DI PALABUHANRATU
}

\author{
Performance of Supply Chain Management of Glass Eel in Supporting Eel Culture Industry in \\ Palabuhanratu
}

Oleh:

\author{
Ronny Irawan Wahjuํㅜ, Tri Wiji Nurani², Robi Komarudin ${ }^{3}$ \\ ${ }^{1}$ Departemen Pemanfaatan Sumberdaya Perikanan, Fakultas Perikanan dan Ilmu Kelautan, Institut Pertanian Bogor. \\ ronnywa@apps.ipb.ac.id \\ 2Departemen Pemanfaatan Sumberdaya Perikanan, Fakultas Perikanan dan Ilmu Kelautan, Institut Pertanian Bogor. \\ tri_wiji@apps.ipb.ac.id \\ ${ }^{3}$ Departemen Pemanfaatan Sumberdaya Perikanan, Fakultas Perikanan dan Ilmu Kelautan, Institut Pertanian Bogor. \\ robi.komarudin@gmail.com
}

* Korespondensi: ronnywa@apps.ipb.ac.id

Diterima: 30 Januari 2021; Disetujui: 5 Maret 2021

\begin{abstract}
The utilization of glass eel in the Cimandiri River Palabuhanratu has a very important role to support the supply chain for the eel culture industry. The purpose of this study was to estimate the amount of glass eel catch, describe the glass eel eel supply chain system, and measure the performance of the supply chain in eel culture. The research method uses quantitative methods through direct observation and interviews, as well as case studies of supply chain actors. The results showed that the highest catch of glass eel in 2019 was in June at an average of 14,859 grams (14.9 $\mathrm{kg})$. The highest catch of glass eel occurred in the dry season (June - August), with a total catch of 21,884 grams $(21.8 \mathrm{~kg})$. The glass eel supply chain mechanism consists of supply chain flow pattern on the product flow, a good and transparent flow of information on each link, and the distribution of two payment systems, namely cash and credit payments. The supply chain performance in the eel culture industry obtained a performance value of 82.63 which indicates that the achievement of the company's supply chain performance is in the good category, and improvements need to be made especially on the deliver process performance indicators with a value of 2.70.
\end{abstract}

Keywords: : glass eel, supply chain, eel, Cimandiri River.

\section{ABSTRAK}

Kegiatan pemanfaatan glass eel (benih sidat) di wilayah Sungai Cimandiri Palabuhanratu memiliki peranan yang sangat penting untuk menunjang rantai pasok industri pembesaran sidat. Tujuan dari penelitian ini adalah mengestimasi jumlah hasil tangkapan glass eel, mendeskripsikan sistem rantai pasok glass eel sidat, serta mengukur kinerja rantai pasok dalam pembesaran sidat. Metode penelitian dengan metode kuantitatif melalui pendekatan observasi langsung dan wawancara, serta studi kasus terhadap pelaku rantai pasok. Hasil penelitian menunjukkan bahwa hasil tangkapan glass eel sidat pada tahun 2019 tertinggi pada bulan Juni rata-rata sebesar 14.859 gram $(14,9 \mathrm{~kg})$. Hasil tangkapan glass eel tertinggi terjadi pada musim kemarau (Juni - Agustus) total hasil tangkapan sebesar $21.884 \mathrm{gram}(21,8 \mathrm{~kg})$. Mekanisme rantai pasok glass eel terdiri dari pola alur rantai pasok pada aliran produk, aliran informasi yang baik dan transparan pada setiap mata rantainya, serta terbaginya dua sistem pembayaran yakni pembayaran secara tunai dan kredit. 
Kinerja rantai pasok pada industri pembesaran sidat diperoleh nilai kinerja sebesar 82,63 yang menunjukkan bahwa pencapaian kinerja rantai pasok perusahaan tergolong kategori baik, dan perbaikan perlu dilakukan terutama pada indikator kinerja proses deliver dengan nilai 2,70.

Kata kunci: benih sidat, rantai pasok, Sungai Cimandiri

\section{PENDAHULUAN}

Ikan sidat (Anguilla sp.) merupakan salah satu ikan yang tergolong ke dalam ordo Anguilliformes dimana di dunia terdapat 18 jenis sidat (Miller \& Tsukamoto 2004). Anguilla bicolor ditemukan di Afrika, India, Indonesia, Malaysia dan Australia (Arai et al. 2012). Dari jumlah tersebut tujuh jenis sidat ditemukan di perairan Indonesia (Sugeha et al. 2006).

Daerah potensial untuk penangkapan benih sidat terutama di barat Sumatera dan selatan Jawa yang berhadapan langsung dengan Samudera Hindia (Affandi et al. 1995). Sungai Cimandiri merupakan salah satu sungai yang berpotensi sebagai habitat ikan sidat (Hakim et al. 2015; Triyanto et al. 2019) Terdapat 3 jenis spesies sidat yang terdapat di perairan ini yakni spesies $A$. bicolor, $A$. marmorata, serta $A$. nebulosa (Hakim et al. 2015). Sidat memiliki gizi yang tinggi dan bernilai ekonomis tinggi, baik untuk pasar lokal maupun ekspor (Noor \& Abidin 2019). Kandungan gizi serta beberapa manfaat dari ikan sidat merupakan salah satu faktor pendorong nelayan dalam menangkapnya (Jamaluddin et al. 2018).

Ketersediaan benih sidat di alam sampai saat ini masih menjadi permasalahan (Widyasari et al. 2013). Permasalahan disebabkan masih kurangnya pendataan jumlah pasokan benih sidat di alam, hal tersebut berdampak terhadap hasil tangkapan yang fluktuatif. Habitat ikan sidat perlu dilindungi terutama dengan meningkatnya upaya penangkapan (Affandi 2005). Nilai estimasi ketersediaan benih sidat di alam dapat membantu industri perihal kebutuhannya dalam rantai pasok (supply chain). Terlebih mengingat semakin bertambahnya industri yang bergerak dibidang pembesaran sidat, yang menyebabkan meningkatnya kebutuhan suplai. Informasi mengenai rantai pasok glass eel menjadi penting karena merupakan integrasi bisnis proses yang utama dari pengguna akhir melalui pemasok yang menyediakan produk, layanan dan informasi dalam menambah nilai bagi pelanggan dan pemangku kepentingan (Lambert \& Cooper 1998). Rantai pasok mencakup kegiatan pengelolaan yang dimulai dari pengadaan bahan baku, penyebaran informasi, pengiriman pesanan hingga pengembangan produk. Ada lima proses manajemen utama supply chain yang didefinisikan dalam model ini yaitu: plan, source, make, deliver, dan return.

Manajemen rantai pasokan memiliki peranan yang sangat penting dalam meningkatkan suatu pelayanan perusahaan kepada pelanggan, baik secara langsung maupun tidak langsung. Supply chain management (SCM) menjadi sangat penting karena tidak hanya berorientasi pada urusan internal sebuah perusahaan, melainkan juga urusan eksternal yang menyangkut hubungan dengan mitra perusahaan. Untuk itu maka diperlukan data kuantitatif ataupun kualitatif atas komoditas yang didistribusikan, baik itu mengenai jumlahnya hingga harga yang dikeluarkan tiap satuan jumlahnya. Kristanto dan Hariastuti (2014) menyebutkan bahwa kondisi supply chain seperti itulah yang diharapkan guna terwujudnya supply chain management (SCM) yang baik. Selain itu, dengan terwujudnya SCM tersebut diharapkan tercipta pula data yang valid mengenai informasi rantai pasok glass eel diantara jaringan pelaku rantai pasok yang meliputi pemasok, pabrik, distributor, pengecer, dan konsumen. Tujuan penelitian ini adalah mengestimasi hasil tangkapan glass eel, mendeskripsikan sistem rantai pasok serta mengukur kinerja rantai pasok pada industri pembesaran sidat.

\section{METODE}

Pengambilan data lapang dilakukan di tingkat nelayan, pengumpul dan industri pembesaran sidat. Nelayan yaitu nelayan yang melakukan penangkapan glass eel di Sungai Cimandiri. Sementara itu untuk pengumpul dan industri pembesaran sidat adalah yang berada di Palabuhanratu Sukabumi. Penelitian dilakukan pada bulan September sampai Desember 2019.

Pengumpulan data dilakukan melalui observasi langsung dan wawancara. Jenis data yang diamati yaitu jumlah hasil tangkapan glass eel sidat, mekanisme rantai pasok pada komoditas glass eel sidat, dan kinerja rantai pasok pada industri pembesaran sidat di 
Palabuhanratu. Data diperoleh dari responden, yaitu 26 nelayan, 1 pengumpul kecil dan 2 pengumpul besar. Informasi yang diperoleh dari responden meliputi informasi sistem rantai pasok (supply chain), serta faktor yang terdapat di dalamnya meliputi jumlah glass eel sidat yang dijual per bulan dan biaya/harga. Untuk data pengukuran kinerja rantai pasok, digunakan data primer yang diperoleh berdasarkan wawancara terhadap salah satu perusahaan industri pembesaran sidat yakni PT. Jawa Suisan Indah.

Analisis data untuk mengestimasi hasil tangkapan glass ee/ dilakukan berdasarkan hasil tangkapan bulanan dari 26 nelayan pada tahun 2019. Hasil tangkapan dijumlahkan per bulan dan juga dikelompokkan ke dalam 4 musim, untuk dapat mengetahui musim penangkapan glass eel di lokasi penelitian.

Setelah mendapatkan data jumlah hasil tangkapan glass eel sidat, kemudian dilakukan analisis kedua yakni analisis Supply Chain Management (SCM). Analisis ini merupakan metode yang digunakan untuk mengidentifikasi mekanisme rantai pasok dalam mendorong profitabilitas dengan meningkatkan pertumbuhan pendapatan melalui peningkatan layanan dan kepuasan pelanggan (Hendricks et al. 2003). Analisis ini digunakan untuk mengetahui aliran rantai pasok glass eel sidat yang ada di Sungai Cimandiri, mulai dari nelayan sebagai pelaku utama penangkapan, nelayan ke pengumpul kecil/pengumpul besar, pengumpul ke perusahaan/industri pembesaran sidat.

Pengukuran kinerja rantai pasok dilakukan dengan menggunakan model SCOR (Supply Chain Operation Reference) (Umami et al. 2015). Pada model SCOR terdapat lima proses yang menjadi faktor penting dalam melakukan analisis diantaranya Plan, Source, Make, Deliver, dan Return (Purnomo 2015). Pengukuran kinerja rantai pasok digambarkan dengan suatu model hirarki seperti dapat dilihat pada Gambar 1.

Adapun penjelasan ke lima proses adalah sebagai berikut:

1. Plan, proses untuk menyeimbangkan permintaan dan pasokan dalam menentukan tindakan terbaik untuk memenuhi kebutuhan pengadaan, produksi dan pengiriman.

2. Source merupakan proses yang dilakukan untuk memenuhi permintaan pengadaan barang maupun jasa.

3. Make, proses untuk mengtransformasi bahan baku menjadi produk yang diinginkan oleh pelanggan.
4. Deliver, proses yang dilakukan dalam memenuhi permintaan terhadap barang maupun jasa.

5. Return merupakan proses pengembalian atau pun menerima kembali pengembalian produk dengan alasan tertentu.

\section{Analisis Kinerja Rantai Pasok}

Metode analisis yang digunakan adalah metode kuantitatif untuk menganalisis hasil pengukuran kinerja rantai pasok perusahaan dengankonfigurasi rantai pasokan serta mendefinisikan cara proses berinteraksi dengan model SCOR (Supply Chain Operation Reference) (Li \& Chen 2011; Umami et al. 2015;). Pada model SCOR terdapat lima proses yang menjadi faktor penting dalam melakukan analisis diantaranya Plan, Source, Make, Deliver, dan Return (Purnomo 2015). Pengukuran kinerja rantai pasok digambarkan dengan suatu model hirarki seperti dapat dilihat pada Gambar 1.

Adapun penjelasan ke lima proses pada Gambar 1 adalah sebagai berikut :

1. Plan, suatu proses untuk keseimbangan antara permintaan dan pasokan dalam menentukan pemenuhan kebutuhan pengadaan, produksi dan pengiriman.

2. Source, suatu proses yang dilakukan untuk memenuhi permintaan pengadaan barang maupun jasa.

3. Make, proses untuk merubah bahan baku menjadi produk yang sesuai permintaan pelanggan.

4. Deliver, proses yang dilakukan dalam memenuhi permintaan terhadap barang maupun jasa.

5. Return, proses pengembalian atau penerimaan kembali produk dengan suatu alasan tertentu.

Setelah tahap pembuatan hirarki pengukuran kinerja rantai pasok, kemudian dilakukan penentuan skor untuk setiap Key Performance Indicator (KPI) dengan proses perhitungan normalisasi Snorm De Boer:

$$
S D B=\frac{(S i-0)}{(\operatorname{Smax}-0) \times(100-\operatorname{Smin})} \ldots \ldots
$$

dengan:

$S D B=$ Dimensi ke-i pada proses ke-i

Si $=$ Nilai kinerja aktual ke-i

Smax = Nilai terbaik ke-i

Smin = Nilai terburuk ke-i

Setelah didapatkan hasil nilai normalisasi dari setiap $\mathrm{KPI}$, selanjutnya dilakukan pembobotan nilai dengan menggunakan matriks banding berpasang mengacu pada metode 
Analytical Hierarchy Process (AHP) (Lockamy 2004). Pemberian bobot nilai pada setiap sel dalam matriks berpasangan menggunakan skala nilai 1 hingga 9 (Tabel 1). Setelah didapatkan nilai bobot pada tiap levelnya, kemudian dilakukan perhitungan nilai akhir dari kinerja rantai pasok. Perhitungan dilakukan dengan cara mengalikan setiap skor normalisasi yang telah didapat dengan bobot dari setiap ruang lingkung KPI, dimensi, dan proses. Nilai akhir adalah nilai kinerja rantai pasok di perusahaan tersebut.

\section{HASIL}

\section{Estimasi jumlah rata-rata hasil tangkapan glass eel sidat per bulan}

Hasil tangkapan glass eel untuk seluruh wilayah Kabupaten Sukabumi pada tahun 2018 sebanyak 7.731.058 ekor, dimana sebanyak 5.812.476 ekor berasal dari Sungai Cimandiri (DKP Kab Sukabumi 2019). Informasi dari nelayan kegiatan penangkapan glass ee/ sidat yang terdapat di Sungai Cimandiri ini sudah berlangsung sejak tahun 1976. Pencatatan hasil tangkapan (logbook) dari setiap nelayan baru dimulai pada tahun 2019. Data hasil tangkapan glass eel dari pengumpul selama tahun 2019 menunjukkan bahwa pada bulan Juni paling banyak tertangkap sebesar 14.859 gram seperti dapat dilihat pada Gambar 2.

Penangkapan glass eel di Sungai Cimandiri dilakukan sepanjang tahun yang dibagi kedalam 4 musim, yaitu musim hujan (Desember-Februari), musim pancaroba I (Maret- Mei), musim kemarau (Juni-Agustus), dan musim pancaroba II (SeptemberNovember). Hasil tangkapan glass eel yang diestimasi dari data hasil tangkapan 26 orang nelayan, dapat dilihat pada Tabel 2 . Berdasarkan data tersebut, terlihat bahwa musim penangkapan glass eel terjadi saat musim kemarau dengan nilai hasil tangkapan sebesar 21.884 gram. Sedangkan pada musim hujan diperoleh hasil tangkapan yang paling sedikit, yaitu sebesar 290 gram.

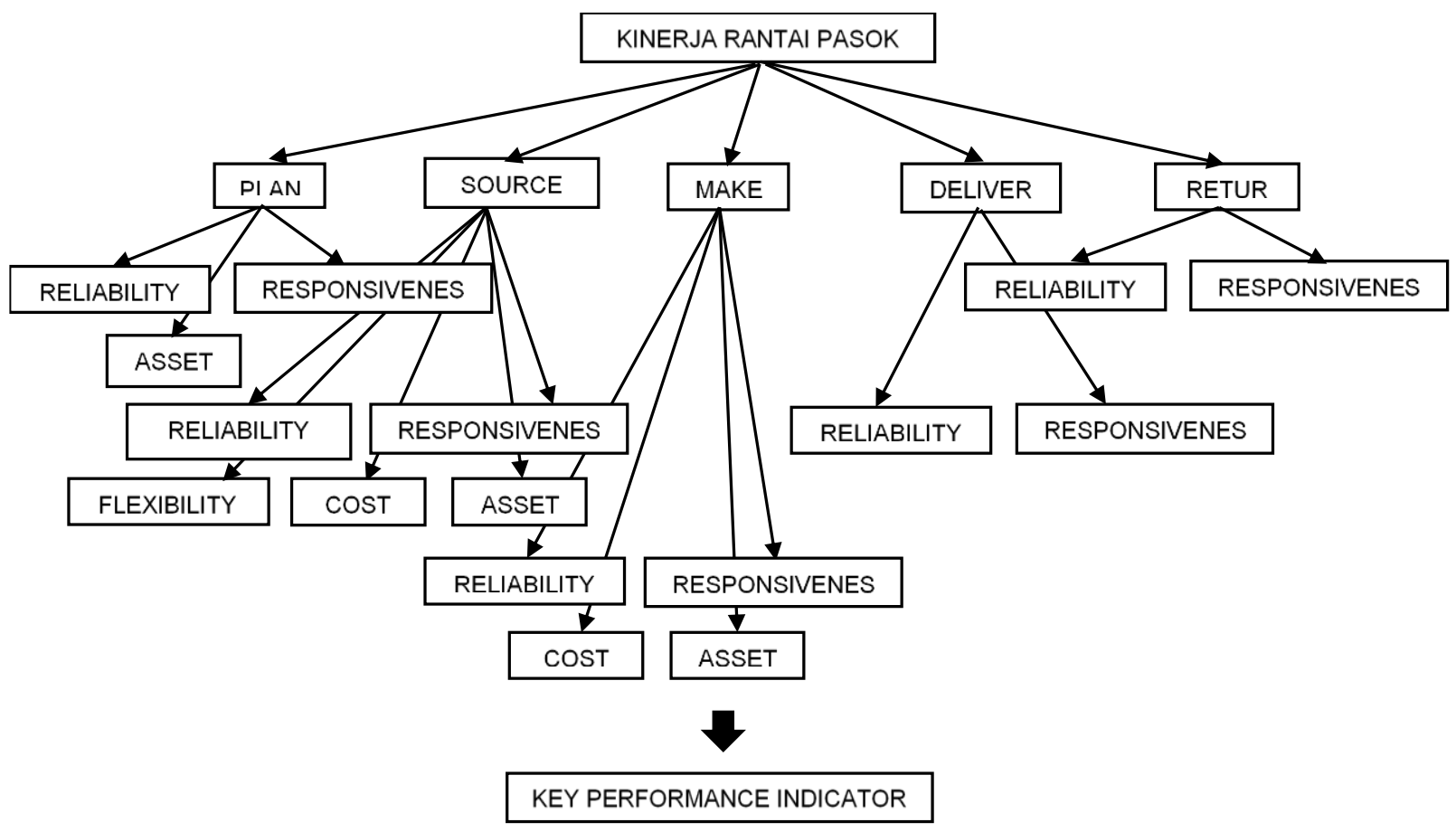

Gambar 1 Hirarki pengukuran kinerja rantai pasok (Purnomo 2015)

Tabel 1 Matriks berpasangan

\begin{tabular}{lccccc}
\hline & Plan & Source & Make & Deliver & Return \\
\hline Plan & 1 & $\mathrm{~N}_{\mathrm{ps}}$ & $\mathrm{N}_{\mathrm{pm}}$ & $\mathrm{N}_{\mathrm{pd}}$ & $\mathrm{N}_{\mathrm{pr}}$ \\
Source & $\mathrm{N}_{\mathrm{sp}}$ & 1 & $\mathrm{~N}_{\mathrm{sm}}$ & $\mathrm{N}_{\mathrm{sd}}$ & $\mathrm{N}_{\mathrm{sr}}$ \\
Make & $\mathrm{N}_{\mathrm{mp}}$ & $\mathrm{N}_{\mathrm{ms}}$ & 1 & $\mathrm{~N}_{\mathrm{md}}$ & $\mathrm{N}_{\mathrm{mr}}$ \\
Deliver & $\mathrm{N}_{\mathrm{dp}}$ & $\mathrm{N}_{\mathrm{ds}}$ & $\mathrm{N}_{\mathrm{dm}}$ & 1 & $\mathrm{~N}_{\mathrm{dr}}$ \\
Return & $\mathrm{N}_{\mathrm{rp}}$ & $\mathrm{N}_{\mathrm{rs}}$ & $\mathrm{N}_{\mathrm{rm}}$ & $\mathrm{N}_{\mathrm{rd}}$ & 1 \\
\hline
\end{tabular}




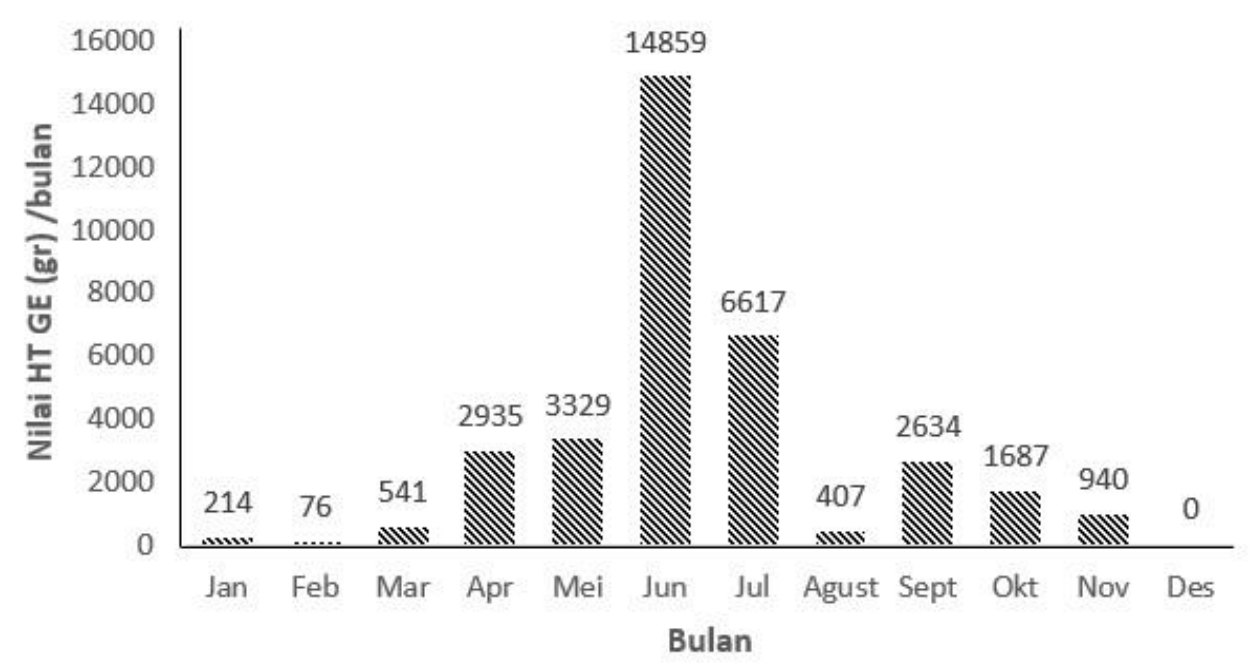

N Jumlah Hasil Tangkapan

Gambar 2 Estimasi hasil tangkapan glass eel sidat per bulan pada tahun 2019

Tabel 2 Estimasi jumlah rata-rata hasil tangkapan glass eel sidat per musim

\begin{tabular}{ccc|ccc|ccc|ccc}
\hline \multicolumn{3}{c|}{ Hujan } & \multicolumn{3}{c|}{ Pancaroba I } & \multicolumn{3}{c|}{ Kemarau } & \multicolumn{3}{c}{ Pancaroba II } \\
Des & Jan & Feb & Mar & Apr & Mei & Jun & Jul & Agt & Sep & Okt & Nov \\
\hline 0 & 214 & 76 & 541 & 2.935 & 3.329 & 14.859 & 6.617 & 407 & 2.634 & 1.687 & 940 \\
\hline \multicolumn{2}{c|}{ Total $=290$} & \multicolumn{3}{c|}{ Total $=6.805$} & \multicolumn{3}{c|}{ Total $=21.884$} & \multicolumn{3}{c|}{ Total $=5.261$} \\
\hline
\end{tabular}

Sumber: Data hasil olahan

\section{Mekanisme Rantai Pasok}

Mekanisme rantai pasok glass eel sidat di Palabuhanratu, Sukabumi bersifaf modern. Hal ini dapat dilihat dari alurnya yang melibatkan nelayan sebagai pemasok glass eel sidat, pengumpul kecil, pengumpul besar, pelanggan, dan industri sebagai processor. Rantai pasokan glass eel sidat di Palabuhanratu terdiri dari anggota primer dan sekunder. Anggota primer rantai pasok glass eel sidat terdiri dari nelayan, pegumpul kecil, pengumpul besar, konsumen dan industri pembesaran sidat.

Gambar 3, menjelaskan bahwa terdapat tiga aliran penting dalam alur rantai pasok yaitu aliran produk, aliran informasi dan aliran uang. Dalam rantai pasok glass eel sidat di Palabuhanratu, terdapat aliran informasi yang dibedakan menjadi dua macam yaitu aliran informasi yang mengalir secara horizontal dan aliran informasi yang mengalir secara vertikal. Aliran informasi secara horizontal hanya terjadi ditingkat nelayan penangkap glass eel sidat. Aliran informasi secara horizontal dikalangan nelayan glass eel ini berupa sharing atau bertukar pendapat terkait lokasi strategis daerah penangkapan glass eel ataupun harga glass ee/ di setiap pengumpul, sebagai informasi untuk dapat meningkatkan hasil tangkapannya. Sedangkan aliran secara vertikal yang terjadi dalam rantai pasok glass eel sidat di Palabuhanratu yakni aliran yang terjadi antar mata rantai dalam ratai pasokan komoditas glass eel sidat meliputi informasi harga jual glass eel sidat, dan penanganan dalam distribusi glass eel sidat.

Aliran uang pada rantai pasok glass eel sidat menunjukan bahwa harga pembelian ditingkat pengumpul paling murah dibanding dengan industri pembesaran sidat. Jika harga glass eel murah yakni sebesar Rp800/gram kebanyakan nelayan lebih memilih untuk tidak mengeluarkan hasil tangkapannya hingga harga kembali normal dengan kisaran Rp1.000/gram, bahkan tindakan lainnya adalah tidak melakukan operasi penangkapan glass ee/ ketika diketahui harga glass eel sidat dipasar sedang mengalami penurunan, sedangkan jika harga glass eel mahal dan volume hasil tangkapan sedikit maka nelayan lebih memilih untuk menjualnya ke pengumpul besar karena lebih untung.

Aliran produk dalam rantai pasokan benih sidat di Palabuhanratu terdiri atas 3 pola yakni pola I (nelayan ke pengumpul besar, pengumpul besar ke PT. JIS), pola II (nelayan ke pengumpul kecil, pengumpul kecil ke pengumpul besar, pengumpul besar ke PT. 
X), pola III (nelayan ke pengumpul kecil, pengumpul kecil ke pengumpul besar, pengumpul besar ke PT. Y), dengan presentase aliran produk glass eel sidat untuk setiap perusahaannya masing-masing sebesar 35\% (PT. JSI), 55\% (PT. X), dan 10\% (PT. $\mathrm{Y})$. Nilai presentase aliran produk glass eel sidat terbesar diperoleh pada industri pembesaran PT. X Banyuwangi. Hal ini disebabkan telah adanya kontrak usaha dengan sistem kerjasama sebelumnya antara pihak pengumpul besar yang menjual glass eel sidat di Palabuhanratu, dengan pihak industri pembesaran sidat di Banyuwangi. Posisi kedua, PT. JSI yang berlokasi di Palabuhanratu dan merupakan satu dari tiga industri pembesaran sidat yang masih beroperasi hingga saat ini, memiliki nilai presentase aliran produk glass eel sidat yang diterima sebesar $35 \%$, dan PT. $Y$ yang berlokasi di Bogor sebesar 10\%. Hal ini diakibatkan, perusahaan tersebut sebagian besar pembesaran sidatnya lebih fokus ke pembesaran sidat dengan spesies Anguilla marmorata dan Anguilla pasifica yang mereka terima pasokannya dari Pulau Sulawesi.

Pada pola I, pasokan benih sidat yang dijual oleh nelayan kepada pengumpul besar berjumlah sekitar $25 \mathrm{~kg} /$ bulan, dengan harga glass eel per gramnya sebesar Rp1.100 per gram. Kemudian dari pengumpul besar ke PT. JIS dengan jumlah pasokan benih yang dijual sekitar $30 \mathrm{~kg} / \mathrm{bulan}$ dengan harga glass eel sidat sebesar Rp2.500 per gram. Pola II, dari nelayan ke pengumpul kecil dengan jumlah glass ee/ yang dijual sekitar 500 gram/hari dan diberi harga Rp1.000 per gram, pengumpul kecil ke pengumpul besar dengan jumlah glass eel yang dijual sekitar $25 \mathrm{~kg} / \mathrm{bulan}$ dan diberi harga Rp1.300 per gram, pengumpul besar ke PT. X dengan jumlah glass eel yang dijual sekitar 40-45 kg/bulan dan harga sebesar Rp6.000 per gram. Pada pola III, nelayan ke pengumpul kecil dan pengumpul kecil ke pengumpul besar memiliki jumlah dan harga glass eel sidat yang diberikan berjumlah sama seperti pada pola II. Hal berbeda, dari pengumpul besar ke PT. $Y$ dengan jumlah glass eel sidat yang dijual sekitar $15 \mathrm{~kg} /$ bulan dan diberi harga sebesar Rp3.500 per gram. Akan tetapi, pada situasi tertentu kemampuan pengumpul (kecil/besar) dalam menerima pasokan glass eel sidat tidak selamanya menerima sesuai dengan nilai jumlah pasokan di atas, melainkan nilai tersebut merupakan nilai maksimal dari penerimaan glass eel sidat yang pengumpul pernah terima.

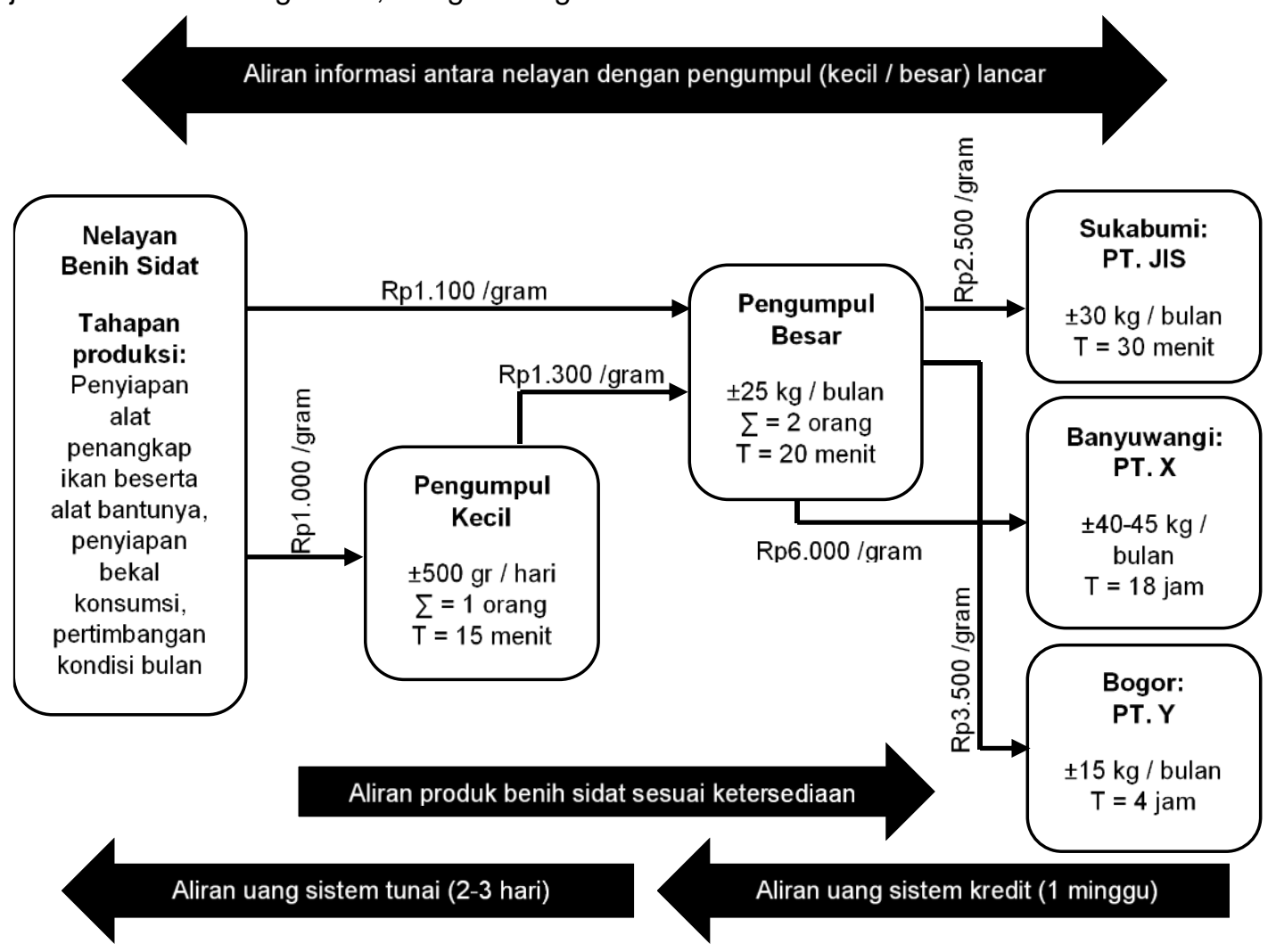

Gambar 3 Pola aliran produk, informasi dan uang dalam rantai pasok glass eel sidat di Palabuhanratu, Sukabumi 


\section{Pengukuran Kinerja Rantai Pasok}

\section{Perhitungan nilai normalisasi}

Perhitungan nilai normalisasi merupakan langkah awal yang dilakukan dalam menganalisis kinerja rantai pasokan. Hal ini disebabkan perhitungan normalisasi memegang peranan yang cukup penting demi tercapainya nilai akhir dari pengukuran performansi. Selain itu, nilai bobot yang berbedabeda pada setiap indikator juga menjadi salah satu faktor pendorong yang mengharuskan dilakukannya perhitungan normalisasi dengan tujuan proses penyamaan parameter. Perhitungan dilakukan pada setiap Key Performance Indicator (KPI) yang tersedia, dan didapatkan rekapitulasi nilai normalisasi seperti pada Tabel 3.

\section{Pembobotan nilai dengan AHP}

Setelah didapatkan nilai skor dari setiap KPI yang ada, tahap berikutnya yakni menentukan bobot nilai pada setiap level menggunakan nilai banding berpasang mengacu pada metode Analytical Hierarchy Process (AHP). Pada Tabel 4 terlihat nilai bobot dari masing-masing kriteria pada proses, dimensi dan KPI.

\section{Perhitungan nilai kinerja rantai pasok}

Pada perhitungan ini dilakukan dengan cara mengalikan setiap skor normalisasi yang telah didapat dengan bobot nilai yang terdapat pada setiap levelnya. Dalam proses perhitungannya dilakukan secara bertahap yakni mulai dari perhitungan key performance indicator (KPI) terlebih dahulu, perhitungan nilai akhir dimensi, hingga terakhir perhitungan nilai total kinerja rantai pasok. Adapun untuk hasil perhitungan ketiga hal tersebut disajikan pada Tabel 5, 6, 7.

Hasil perhitungan kinerja rantai pasok industri pembesaran sidat di PT. Jawa Suisan Indah adalah sebesar 82,63 dan tergolong kategori baik. Adapun rincian nilai tertinggi terdapat pada proses source dengan nilai sebesar 44,04, hal ini disebabkan perusahaan mampu memaksimalkan nilai aktual dari proses source-responsiveness, sourceflexibility, source-cost, dan source-asset. Disusul proses plan dengan nilai sebesar 20,46 yang disebabkan tidak tercapainya nilai aktual pada proses plan-responsiveness. Proses make memperoleh nilai kinerja sebesar 11,82. Hal tersebut diakibatkan, proses make-responsiveness perusahaan yang belum dapat tanggap dalam memproduksi pesanan yang bervariasi. Nilai kedua terendah adalah sebesar 3,61 pada proses return yang disebabkan rendahnya skor pada proses return-reliability. Adapun upaya peningkatan kinerja rantai pasok perusahaan tetap perlu dilakukan dan lebih diprioritaskan pada proses deliver. Hal ini disebabkan proses tersebut memiliki nilai kinerja yang paling rendah yakni sebesar 2,70 sehingga perbaikan perlu difokuskan pada proses deliver-reliability dalam mencapai nilai aktual untuk tingkat pemenuhan persediaan produk jadi siap kirim dan lead time produk jadi.

Tabel 3 Rekapitulasi nilai normalisasi Key Performance Indicator (KPI)

\begin{tabular}{lllc}
\hline $\begin{array}{c}\text { Proses (level } \\
\text { 1) }\end{array}$ & \multicolumn{1}{c}{$\begin{array}{c}\text { Dimensi } \\
\text { (level 2) }\end{array}$} & \multicolumn{1}{c}{ KPI (level 3) } & Skor \\
\hline Plan & Reliability & Pertemuan dengan pelanggan & 100 \\
& & Waktu mengidentifikasi kinerja karyawan & 100 \\
& Responsiveness & Jangka waktu penjadwalan produksi & 80 \\
& & Jangka waktu mengidentifikasi spesifikasi produk baru & 60 \\
Source & Asset & Cash to cash cycle time & 100 \\
& Reliability & Kecacatan bahan baku & 60 \\
& & Pemenuhan bahan baku & 60 \\
& Responsiveness & Kehandalan dalam pengiriman & 80 \\
& Flexibility & Ketersediaan supplier & 100 \\
& Cost & Biaya order ke supplier & 100 \\
\multirow{4}{*}{ Make } & Asset & Persediaan harian & 100 \\
& Reliability & Kesalahan dalam pengepakan & 100 \\
& & Jumlah produk cacat & 95 \\
& Responsiveness & Waktu pembuatan produk & 60 \\
& & Ketanggapan memproduksi pesanan yang bervariasi & 100 \\
Deliver & Asset & Lama rata-rata masa pakai alat produksi & 20 \\
& Reliability & Tingkat pemenuhan persediaan produk jadi siap kirim & 60 \\
Return & Responsiveness & Tingkat kehabisan produk & 30 \\
& Reliabilty & Lead time produk jadi & 90 \\
& Responsiveness & Tingkat komplain dari pelanggan & 30 \\
& & Waktu untuk mengganti produk yang rusak & 60 \\
\hline
\end{tabular}


Tabel 4 Nilai bobot tiap level di PT. Jawa Suisan Indah

\begin{tabular}{|c|c|c|c|c|c|}
\hline Proses (level 1) & Bobot & $\begin{array}{l}\text { Dimensi } \\
\text { (level 2) }\end{array}$ & Bobot & $\begin{array}{c}\text { KPI } \\
\text { (level 3) }\end{array}$ & Bobot \\
\hline \multirow[t]{5}{*}{ Plan } & \multirow[t]{5}{*}{0,24} & \multirow[t]{2}{*}{ Reliability } & \multirow{2}{*}{0,11} & PR-1 & 0,75 \\
\hline & & & & PR-2 & 0,25 \\
\hline & & \multirow{2}{*}{ Responsiveness } & \multirow{2}{*}{0,63} & PR-3 & 0,75 \\
\hline & & & & PR-4 & 0,25 \\
\hline & & Asset & 0,26 & PA & 1 \\
\hline \multirow[t]{7}{*}{ Source } & \multirow[t]{7}{*}{0,48} & \multirow[t]{3}{*}{ Reliability } & \multirow{3}{*}{0,23} & SR-1 & 0,11 \\
\hline & & & & SR-2 & 0,63 \\
\hline & & & & SR-3 & 0,26 \\
\hline & & Responsiveness & 0,09 & SR-4 & 1 \\
\hline & & Flexibility & 0,26 & SF & 1 \\
\hline & & Cost & 0,22 & SC & 1 \\
\hline & & Asset & 0,20 & SA & 1 \\
\hline \multirow[t]{5}{*}{ Make } & \multirow[t]{5}{*}{0,17} & \multirow[t]{2}{*}{ Reliability } & 025 & MR-1 & 0,25 \\
\hline & & & 0,25 & MR-2 & 0,75 \\
\hline & & \multirow[t]{2}{*}{ Responsiveness } & 0.47 & MR-3 & 0,75 \\
\hline & & & $0,4 /$ & MR-4 & 0,25 \\
\hline & & Asset & 0,28 & MA & 1 \\
\hline \multirow[t]{3}{*}{ Deliver } & \multirow[t]{3}{*}{0,07} & \multirow[t]{2}{*}{ Reliability } & 0,17 & DR-1 & 0,25 \\
\hline & & & 0,17 & DR-2 & 0,75 \\
\hline & & Responsiveness & 0,83 & DR-3 & 1 \\
\hline \multirow[t]{2}{*}{ Return } & \multirow{2}{*}{0,04} & Reliability & 0,25 & RR-1 & 1 \\
\hline & & Responsiveness & 0,75 & RR-2 & 1 \\
\hline
\end{tabular}

Tabel 5 Perhitungan nilai akhir KPI

\begin{tabular}{|c|c|c|c|c|c|c|}
\hline Proses & Dimensi & KPI & Skor & Bobot & Nilai Akhir & Total \\
\hline \multirow[t]{5}{*}{ Plan } & Reliability & PR-1 & 100 & 0,75 & 75 & \multirow{2}{*}{100} \\
\hline & & PR-2 & 100 & 0,25 & 25 & \\
\hline & Responsiveness & PR-3 & 80 & 0,75 & 60 & \multirow{2}{*}{75} \\
\hline & & PR-4 & 60 & 0,25 & 15 & \\
\hline & Asset & PA & 100 & 1 & 100 & 100 \\
\hline \multirow[t]{7}{*}{ Source } & Reliability & SR-1 & 60 & 0,11 & 6,37 & \multirow{3}{*}{65,21} \\
\hline & & SR-2 & 60 & 0,63 & 38 & \\
\hline & & SR-3 & 80 & 0,26 & 20,84 & \\
\hline & Responsiveness & SR-4 & 100 & 1 & 100 & 100 \\
\hline & Flexibility & SF & 100 & 1 & 100 & 100 \\
\hline & Cost & SC & 100 & 1 & 100 & 100 \\
\hline & Asset & SA & 100 & 1 & 100 & 100 \\
\hline \multirow[t]{5}{*}{ Make } & Reliability & MR-1 & 95 & 0,25 & 23,75 & \multirow{2}{*}{68,75} \\
\hline & & MR-2 & 60 & 0,75 & 45 & \\
\hline & Responsiveness & MR-3 & 100 & 0,75 & 75 & \multirow{2}{*}{80} \\
\hline & & MR-4 & 20 & 0,25 & 5 & \\
\hline & Asset & MA & 60 & 1 & 60 & 60 \\
\hline \multirow[t]{3}{*}{ Deliver } & Reliability & DR-1 & 30 & 0,25 & 7,5 & \multirow{2}{*}{75} \\
\hline & & DR-2 & 90 & 0,75 & 67,5 & \\
\hline & Responsiveness & DR-3 & 30 & 1 & 30 & 30 \\
\hline \multirow[t]{2}{*}{ Return } & Reliability & RR-1 & 60 & 1 & 60 & 60 \\
\hline & Responsiveness & RR-2 & 100 & 1 & 100 & 100 \\
\hline
\end{tabular}

Tabel 6 Perhitungan nilai akhir dimensi

\begin{tabular}{|c|c|c|c|c|c|}
\hline Proses & Dimensi & Skor & Bobot & Nilai Akhir & Total \\
\hline \multirow[t]{3}{*}{ Plan } & Reliability & 100 & 0,11 & 11 & \multirow{3}{*}{84,17} \\
\hline & Responsiveness & 75 & 0,63 & 47 & \\
\hline & Asset & 100 & 0,26 & 26 & \\
\hline \multirow[t]{5}{*}{ Source } & Reliability & 65,21 & 0,23 & 15,29 & \multirow{5}{*}{91,85} \\
\hline & Responsiveness & 100 & 0,09 & 9 & \\
\hline & Flexibility & 100 & 0,26 & 26 & \\
\hline & Cost & 100 & 0,22 & 22 & \\
\hline & Asset & 100 & 0,20 & 20 & \\
\hline \multirow[t]{3}{*}{ Make } & Reliability & 68,75 & 0,25 & 17,22 & \multirow{3}{*}{71,50} \\
\hline & Responsiveness & 80 & 0,47 & 37,27 & \\
\hline & Asset & 60 & 0,28 & 17,01 & \\
\hline \multirow[t]{2}{*}{ Deliver } & Reliability & 75 & 0,17 & 12,50 & \multirow[b]{2}{*}{37,50} \\
\hline & Responsiveness & 30 & 0,83 & 25 & \\
\hline \multirow[t]{2}{*}{ Return } & Reliability & 60 & 0,25 & 15 & \multirow{2}{*}{90} \\
\hline & Responsiveness & 100 & 0,75 & 75 & \\
\hline
\end{tabular}


Tabel 7 Perhitungan nilai kinerja rantai pasok

\begin{tabular}{cccc}
\hline Proses & Skor & Bobot & Nilai Akhir \\
\hline Plan & 84,17 & 0,24 & 20,46 \\
Source & 91,85 & 0,48 & 44,04 \\
Make & 71,50 & 0,17 & 11,82 \\
Deliver & 37,50 & 0,07 & 2,70 \\
Return & 90 & 0,04 & 3,61 \\
\hline & Total & & 82,63 \\
\hline
\end{tabular}

\section{PEMBAHASAN}

Alat tangkap yang digunakan untuk menangkap glass eel di Sungai Cimandiri yaitu seser dan sirib. Sidat merupakan salah satu biota perairan yang memiliki sifat katadromus dimana siklus hidup sidat dimulai dari fase dewasa (adult eel) yang bermigrasi ke laut untuk melakukan pemijahan hingga menghasilkan larva yang terbawa oleh arus ke arah pesisir pantai atau pun muara sungai dan berkembang menjadi glass eel (Usui 2004). Glass eel merupakan fase ketiga dalam hidup sidat setelah sebelumnya melewati fase telur dan larva yang kemudian akan menjadi sidat sepenuhnya pada fase dewasa. Operasi penangkapan glass ee/ sidat ini tidak dilakukan setiap hari, melainkan hanya pada setiap satu pekan terakhir dari tiap bulannya bersamaan dengan fase bulan gelap disaat glass eel beruaya memasuki perairan tawar (Davey \& Jellyman 2005). Ruaya dari glass eel dipengaruhi oleh arus sungai, pasang surut dan fase bulan (Martin 1995; Edeline et al., 2005; Haryono \& Wahyudewantoro 2016; Suhendar et al, 2016; Imron et al., 2018) dan suhu perairan (Edeline et al.2006). Hasil tangkapan tertinggi glass eel terjadi pada musim kemarau. Sedikitnya hasil tangkapan pada musim hujan juga ditemukan di Sungai Bungur Kabupaten Pandeglang dimana pada musim penghujan dengan gelombang yang tinggi sehingga tidak ditemukan glass eel. Boivin et al (2015) menyatakan bahwa faktor lingkungan yang berpengaruh terhadap ruaya benih ikan sidat ke sungai diantaranya kecepatan arus, gradient salinitas serta pasang surut air laut. Kedua faktor tersebut secara tidak langsung berkaitan dengan gelombang air laut dimana semakin besar gelombang semakin sedikit benih sidat yang memasuki sungai (Haryono \& Wahyudewantoro, 2016).

Ikan sidat yang mempunyai kebiasaan hidup memijah dilaut yang hangat pada kedalaman sekitar $400 \mathrm{~m}$ (Matsui 1982). Benih sidat akan masuk muara sungai pada malam hari ketika pasang tinggi dan salinitas di muara sungai rendah (Dou \& Tsukamoto
2003). Terbatasnya penangkapan yang hanya dilakukan dalam seminggu akan berpengaruh terhadap sediaan glass eel di level pembesaran yang memiliki kapasitas tampung yang terbatas. Perusahaan akan memberhentikan permintaan glass eel bila kapasitas kolam sudah terpenuhi.

Rantai pasok sidat dipengaruhi oleh anggota primer yang langsung terlibat dalam kegiatan rantai pasokan sedangkan anggota sekunder yang tidak langsung berhubungan dengan kegiatan produksi namun berpengaruh dalam bisnis (Subarkah 2009). Dalam rantai pasok sidat penangkap, pengum-pul kecil dan pengumpul besar terlibat langsung dalam kegiatan bisnis rantai pasokan. Sementara anggota primer merupakan anggota rantai pasokan yang tidak langsung berhubungan dengan kegiatan produksi namun memiliki pengaruh dalam kegiatan bisnis dalam hal ini institusi yang terkait dengan peraturan penangkapan sidat. Koordinasi antar anggota didasari oleh kesadaran bahwa kuatnya rantai pasokan tergantung pada kekuatan seluruh elemen yang terlibat di dalamnya. Menurut Pujawan dan Mahendrawathi (2017), aliran informasi sangat penting dalam rantai pasok sidat karena informasi menjadi dasar pelaksanaan proses rantai pasok. Selain itu, informasi harus memiliki beberapa karakteristik agar berguna dalam mengambil suatu keputusan rantai pasok, yaitu: akurat, tepat dan dapat diakses saat dibutuhkan (Chopra dan Meindl 2007).

Aliran produk glass eel sidat yang dihasilkan oleh nelayan di Palabuhanratu melibatkan pengumpul kecil, pengumpul besar, hingga industri pembesaran sidat. Pada tahap produksi ditingkat nelayan sumber sarana produksi berasal dari alam, yakni nelayan langsung menangkap glass eel dari sungai Cimandiri. Pada tahap produksi dilakukan mulai dari penyiapan alat penangkapan ikan, penentuan waktu penangkapan, penangkapan, dan penjualan. Mekanisme rantai pasok dapat digolongkan menjadi dua bagian yakni dapat bersifat tradisional ataupun modern. Mekanisme tradisional 
adalah mekanisme dimana petani menjual produknya langsung ke pasar atau lewat tengkulak, sedangkan mekanismne rantai pasok modern melibatkan manufaktur, pasar swalayan, dan pedagang besar (Marimin dan Magfiroh 2013).

Sistem pembayaran pada pembelian benih sidat dilakukan secara bertahap yang dilakukan oleh pengumpul kecil ataupun pengumpul besar dengan pihak industri pembesaran sidat. Harga jual glass eel sidat ditingkat nelayan sangat bervariasi tergantung pada musim benih sidat serta daya tampung pembesaran sidat. Mekanisme aliran uang pada rantai pasok glass ee/ sidat di Palabuhanratu lebih ditekankan pada bagaimana sistem transaksi pembayaran yang digunakan baik tunai maupun kredit oleh masing-masing mata rantai. Adapun aliran uang yang terdapat pada rantai pasok benih sidat di Palabuhanratu terbagi menjadi dua bentuk. Di antaranya sistem pembayaran secara tunai pada tingkat nelayan dengan pengumpul kecil/besar, sedangkan pada tingkat pengumpul besar dengan industri pembesaran terjadi sistem pembayaran secara kredit. Ketiga aliran tersebut merupakan salah satu faktor yang sangat penting dalam penentuan proses pengendalian mutu, meliputi proses distribusi barang mulai dari hulu hingga hilirnya yang dalam hal ini adalah konsumen (Jati el al. 2014). Aliran uang adalah salah satu aspek lainnya yang harus ada dalam rantai pasok suatu komoditas. Aliran uang merupakan aliran yang di dalamnya terdapat penyaluran nilai dalam bentuk materi. Aliran keuangan tersebut terdiri dari komponen biaya dan keuntungan yang diterima oleh pelaku yang terlibat dalam mata rantai pasok (Kurniawan et al. 2013). Aliran uang yang terdapat pada rantai pasok glass eel sidat di Palabuhanratu terdiri dari dua bentuk yaitu sistem pembayaran secara tunai yang dilakukan antara nelayan dengan pengumpul kecil.

Pengukuran kinerja di dalam rantai pasok sangat penting dilakukan pada tingkat industri-industri yang ingin meningkatkan kompetensinya sebagai industri yang kuat. Industri-industri pada umumnya melakukan pengukuran performansi terhadap rantai pasok dengan tujuan untuk mengurangi biayabiaya, memenuhi kepuasan pelanggan dan meningkatkan keuntungan. Menurut Chan (2003), mengatakan bahwa pengukuran kinerja merupakan suatu proses dalam mengukur efektivitas dan efisiensi suatu tindakan. Hal ini memainkan peranan yang cukup penting dalam mengawasi kinerja, meningkatkan motivasi dan komunikasi, dan mendiagnosis masalah serta membantu mengidentifikasi keberhasilan dan potensi strategi pengelolaan.

\section{KESIMPULAN}

1. Estimasi jumlah hasil tangkapan glass eel pada tahun 2019 tertinggi terjadi pada musim kemarau dengan total hasil tangkapan 21.884 gram $(21,8 \mathrm{~kg})$, sedangkan secara bulanan tertinggi terjadi pada bulan Juni sebesar 14.859 gram $(14,9 \mathrm{~kg})$.

2. Mekanisme rantai pasok pada komoditas benih sidat di Palabuhanratu terdapat tiga aliran yaitu aliran aliran produk, aliran informasi dan aliran uang. Tiga pola alur rantai pasok pada aliran produk, aliran informasi yang cukup lancar dan transparan pada setiap mata rantainya, serta terbaginya dua sistem pembayaran yang terdapat pada aliran uang yakni sistem pembayaran tunai dan sistem pembayaran secara kredit.

3. Kinerja rantai pasok pada industri pembesaran sidat memiliki nilai kinerja sebesar 82,63 yang menunjukkan bahwa pencapaian kinerja rantai pasok perusahaan tergolong kategori baik, dan perlunya perbaikan untuk indikator yang memiliki nilai kinerja rendah yakni pada proses deliver yang bernilai 2,70.

\section{SARAN}

Perlu dilakukan penelitian lanjutan dalam mengukur suply chain management untuk menciptakan keunggulan dalam persaingan di pasar internasional.

\section{UCAPAN TERIMA KASIH}

Ucapan terima kasih disampaikan kepada PT Jawa Suisan Indah yang telah membantu dalam pelaksanaan pengumpulan data selama penelitian.

\section{DAFTAR PUSTAKA}

Affandi R, Rahardjo MF, Sulistiono. 1995. Distribusi Juvenile Ikan Sidat (Anguilla spp) di Perairan Segara Anakan Cilacap, Jawa Tengah. Jurnal IImu-IImu Perairan dan Perikanan 3(1): 27-38.

Affandi R. 2005. Strategi Pemanfaatan Sumber Daya Ikan Sidat. Jurnal Ikhtiologi Indonesia. 5(2): 77-81. 
Arai T, Chino N, Zulkifli SZ, Ismail A. 2012. Notes on the Occurrence of the Tropical Eels Anguilla Bicolor Bicolor in Peninsular Malaysia. Jurnal of Fish Biology. 80(3): 692-697.

Boivin B, Castonguay M, Audet C, Pavey SA, Dionne M, Bernachez L. 2015. How does Salinity Influence Habitat Selection and Growth in Juvenile American Eel Anguilla Rostrata? J. Fish. Biol. 86: 765 - 784.

Chan FTS. 2003. Performance Measurement in a Supply Chain. The International Journal of Advanced Manufacturing Technology. 21: 534 - 548.

Chopra S, Meindl P. 2007. Supply Chain Management: Strategy, Planning and Operation. United States of America (US): Pearson Prentice Hall.

Davey AJH, Jellyman DJ. 2005. Sex Determination in Freshwater Eels and Management Option for Manipulation. Reviews in Fish Biology and Fisheries.15: 37-52.

Dinas Kelautan dan Perikanan. 2019. Rekap Data Sidat Kabupaten Sukabumi 2018. Dinas Kelautan dan Perikanan Palabuhanratu. Sukabumi.

Dou SZ, Tsukamoto K. 2003. Observations on the Nocturnal Activity and Feeding Behavior of Anguilla Japonica Glass Eel under Laboratory Conditions. Environmental Biology of Fishes. 67: 389-395.

Edeline E, Dufour S, Elie P. 2005. Role of Glass Eel Salinity Preference in the Control of Habitat Selection and Growth Llasticity in Anguilla Anguilla. Mar. Ecol. Prog. Ser. 304: 191-199.

Edeline E, Lambert P, Rigaud C, Ellie P. 2006. Effects of Body Condition and Water Temperature on Anguilla Anguilla Glass Eel Migratory Behavior. J. Exp. Mar. Biol. Ecol. 331: 217-225.

Fahmi MR, Hirnawati R. 2010. Keragaman Ikan Sidat Tropis (Anguilla sp.) di Perairan Sungai Cimandiri, Pelabuhan Ratu, Sukabumi. [Prosiding]. Depok (ID): Forum Inovasi Teknologi Akuakultur. 1-8.

Hakim AA, Kamal MM, Butet NA, Affandi R. 2015. Komposisi Spesies Ikan Sidat (Anguilla sp.) di Delapan Sungai yang Bermuara ke Teluk Palabuhanratu, Sukabumi, Indonesia. Jurnal IImu dan
Teknologi Kelautan Tropis. 7(2): 573 585.

Haryono, Wahyudewantoro G. 2016. Pemetaan Habitat Ruaya Benih Ikan Sidat (Anguilla bicolor) dan Potensinya di Pantai Selatan Jawa. OmniAkuatika.12(3): 47 - 58.

Hendricks, Kevin B, Vinod R, Singhal. 2003. The Effects of Supply Chain Glitches on Shareholder Wealth. Jurnal of Operation Management. 21(5): 501522.

Imron M, Putra RR, Baskoro MS, Soeboer DA. 2018. Usaha Penangkapan Benih Sidat Menggunakan Alat Tangkap Seser di Muara Cibuni-Tegal Buleud-Sukabumi Jawa Barat. Jurnal Albacore. 2(3): 295 $-305$.

Jamaluddin, Widodo A, Mufliha N. 2018. Vitamin A Ikan Sidat (Anguilla marmorata) Asal Sungai Palu dan Danau Poso. Jurnal Gizi dan Kesehatan. 2(1): $24-30$.

Jati AK, Nurani TW, Iskandar BH. 2014. Sistem Rantai Pasok Tuna Loin di Perairan Maluku. Journal Marine Fisheries. 5(2): 171 - 180.

Kristanto BR, Hariastuti NLP. 2014. Aplikasi Model House of Risk (HOR) untuk Mitigasi Risiko pada Supply Chain Bahan Baku Kulit. Jurnal IImiah Teknik Industri. 13(2): 149 - 157.

Kurniawan RDA, Suwandari, Ridjal JA. 2013. Analisis Rantai Pasokan (Supply Chain) Komoditas Cabai Merah Besar di Kabupaten Jember. Jurnal Berkala IImiah Pertanian. 9(9): $10-17$.

Lambert DM, Cooper MC, Pagh JD. 1998. "Supply Chain Management: Implementation Issues and Research Opportunities". The International Journal of Logistics Management. (9)2: $1-20$

Ling Li QS, Xu Chen.2011. Ensuring Supply Chain Quality Performance through Applying the SCOR model. International Journal of Production Research. 49(1):33-57.

Lockamy A, Kevin M. 2004. Linking SCOR Planning Practices to Supply Chain Performance. International Journal of Operations \& Production Management. 24(11/12): 1192-1218.

Marimin, Maghfiroh N. 2013. Aplikasi Teknik Pengambilan Keputusan dalam 
Manajemen Rantai Pasok. Bogor (ID): IPB Press.

Martin, MH. 1995. The Effects of Temperature, River Flow and Tidal Cycles on the Onset of Glass Eel and Elver Migration into Fresh Water in the American Eel. J. Fish. Biol. 46: 891902.

Miller MJ, Tsukamoto K. 2004. An Introduction on Leptocephali: Biology and Identification. Ocean Research Institute. University of Tokyo. Tokyo

Noor AYM, Abidin Z. 2019. Daya Saing Ikan Sidat (Anguilla sp) Indonesia di Pasar International. Journal of Economic and Social of Fisheries and Marine. 07(01): 44-58.

Pujawan IN, Mahendrawathi. 2017. Supply Chain Management Edisi 3. Yogyakarta (ID): Penerbit Andi Yogyakarta.

Purnomo A. 2015. Analisis Kinerja Rantai Pasok Menggunakan Metode Supply Chain Operation Reference (SCOR) di Industri Tekstil dan Produk Tekstil Sektor Industri Hilir (Studi kasus pada perusahaan garmen PT Alas Indah Remaja Bogor). [Prosiding]. Bandung (ID): Universitas Pasundan.

Subarkah A. 2009. Kajian Kinerja Rantai Pasokan Letuce Head dengan Menggunakan DEA. [Skripsi]. Bogor (ID): Institut Pertanian Bogor.
Sugeha HY, Aoyama J, Tsukamoto K. 2006. Downstream Migration of Tropical Anguillid Silver Eels in the Poso Lake, Central Sulawesi Island, Indonesia.Prosiding Seminar Limnologi. 267-275.

Suhendar D, Wahju RI, Soeboer DA. 2016. Pengaruh Fase Bulan terhadap Hasil Tangkapan Glass Eel di Muara Sungai Cibuni Tegal Buleud, Kabupaten Sukabumi. Jurnal Teknologi Perikanan dan Kelautan. 7(1): 39-46.

Triyanto, Affandi R, Kamal MM, Haryani GS. 2019. Fungsi Rawa Pesisir sebagai Habitat Sidat Tropis Anguilla spp di Estuari Sungai Cimandiri Sukabumi Jawa Barat. Jurnal IImu dan Teknologi Kelautan Tropis. 11(2): 475-492.

Umami MR, Iskandar R, Suryadi U. 2015. Analisis Kinerja Supply Chain Menggunakan Model SCOR (Studi Kasus pada Roti "SIP" Politeknik Negeri Jember). Jurnal IImiah INOVASI. 15(3): $66-74$.

Usui A. 2004. Eel Culture Translated by Ichiro Hayashi. London (UK): Fishing News Books.

Widyasari RAHE, Kusharto CM, Wiryawan B, Wiyono ES, Suseno SH. 2013. Pemanfaatan Limbah Ikan Sidat Indonesia (Anguilla bicolor) sebagai Tepung pada Industri Pengolahan Ikan di Palabuhanratu, Kabupaten Sukabumi. Jurnal Gizi dan Pangan. 8(3): $215-220$. 